\title{
MAGNETIC MOLECULAR CHARGE TRANSFER COMPLEXES
}

SAILESH R. CHITTIPEDDI and ARTHUR J. EPSTEIN*

Departments of Physics and Chemistry, The Ohio State University, Columbus, $\mathrm{OH}$ 43210-1106 (U.S.A.)

JIAN H. ZHANG and WILLIAM M. REIFF

Department of Chemistry, Northeastern University, Boston, MA 02115 (U.S.A.)

IVAR HAMBERG and DAVID B. TANNER

Department of Physics, University of Florida, Gainesville, FL 32611 (U.S.A.)

DAVID C. JOHNSON and JOEL S. MILLER*

Central Research and Development Department, E. I. du Pont de Nemours and

Company, Inc., Experimental Station E328, Wilmington, DE 19898 (U.S.A.)

\section{ABSTRACT}

The charge transfer complex $\left[\mathrm{Fe}\left(\mathrm{C}_{5} \mathrm{M} \theta_{5}\right)_{2}\right]^{+\cdot} \cdot[\mathrm{TCNE}]^{-*} *$ unlike either $\left[\mathrm{Co}\left(\mathrm{C}_{5} \mathrm{Me}_{5}\right)_{2}\right]^{+}[\mathrm{TCNE}]^{-}$or $\left[\mathrm{Fe}\left(\mathrm{C}_{5} \mathrm{Me}_{5}\right)_{2}\right]^{+} \cdot\left[\mathrm{C}_{3}(\mathrm{CN})_{5}\right]^{-}$exhibits spontaneous magnetization in zero applied field and is a bulk ferromagnet. These three compounds possess the same structural motif, namely, linear chains of alternating cationic donors and anionic acceptors. The high temperature magnetic susceptibility obeys the CurieWeiss expression with $\theta=+30,-1.0$, and $-1.2 \mathrm{~K}$, respectively, and the latter pair of complexes possess weak antiferromagnetic coupling. The ferromagnet exhibits zero field Zeeman split $57 \mathrm{Fe}$ Mossbauer spectra with an internal field of $425.6 \mathrm{kOe}$ at $4.23 \mathrm{~K}$.

\section{INTRODUCTION}

We have deliberately sought to prepare a molecular-based ground state bulk ferromagnet since our observation that 1-D 1:1 $\left[\mathrm{Fe}\left(\mathrm{C}_{5} \mathrm{Me}_{5}\right)_{2}\right]^{+\cdot}[\mathrm{TCNQ}]^{-*}$ exhibited metamagnetic behavior [1]. Using permethylated metallocenium cations we have prepared a series of charge transfer complexes with a variety of radical anion acceptors in order to elucidate the critical structure-function relationships that might ultimately lead to the preparation of a molecular-based ferromagnet. With the specific goal of increasing the spin density we sought a smaller planar radical anion and selected $S=1 / 2$

\footnotetext{
* Abbreviations: $\mathrm{TCNE}=$ tetracyanoethylene, $(\mathrm{NC})_{2} \mathrm{C}=\mathrm{C}(\mathrm{CN})_{2} ; \mathrm{TCNQ}=7,7,8,8$ -
} tetracyano-p-quinodimethane, $p-\left(\mathrm{NC}_{2} \mathrm{CC}_{6} \mathrm{H}_{4} \mathrm{C}(\mathrm{CN})_{2}\right.$. 
tetracyanoethyleneide, [TCNE] ${ }^{-}$. Herein we summarize the structure, ${ }^{57} \mathrm{Fe}$ Mossbauer, and field-dependent magnetic susceptibility data of the TCNE salt of decamethylferrocene, $\left[\mathrm{Fe}\left(\mathrm{C}_{5} \mathrm{Me}_{5}\right)_{2}\right]^{+} \cdot[\mathrm{TCNE}]^{-}$, which characterizes this charge transfer salt as a 3-D ground state ferromagnet [2].

\section{RESULTS}

Structure

The $\left[\mathrm{Fe}\left(\mathrm{C}_{5} \mathrm{Me}_{5}\right)_{2}\right]^{+\cdot} \cdot[\mathrm{TCNE}]^{-},\left[\mathrm{Co}\left(\mathrm{C}_{5} \mathrm{Me}_{5}\right)_{2}\right]^{+}[\mathrm{TCNE}]^{-}$, and $\left[\mathrm{Fe}\left(\mathrm{C}_{5} \mathrm{Me}_{5}\right)_{2}\right]^{+\cdot}\left[\mathrm{C}_{3}(\mathrm{CN})_{5}\right]^{-}$ possess the same structural motif where the cation metallocene donors, $D$, and anion

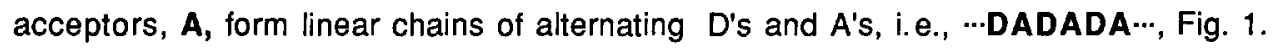
There are no intermolecular interactions less than the sum of the van der Waal radii.
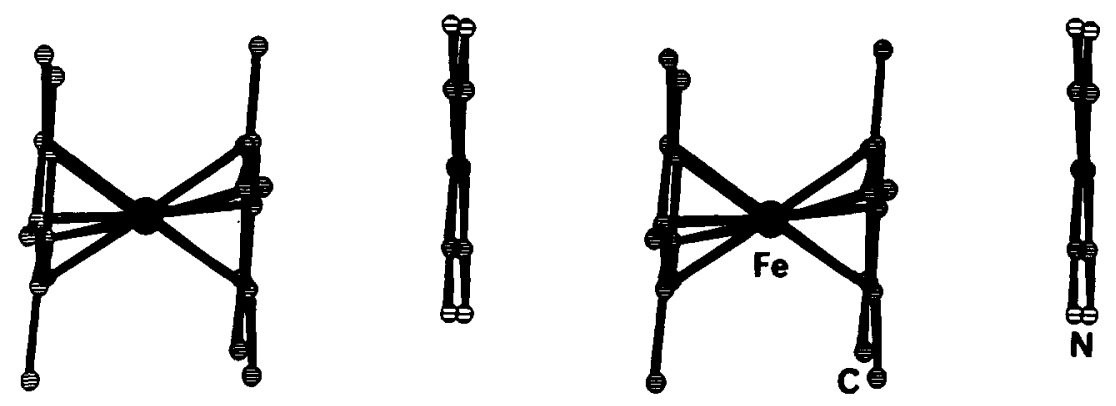

Fig. 1. Alternating donor/acceptor structure of 1-D $\left.\left[\mathrm{Fe}\left(\mathrm{C}_{5} \mathrm{Me}\right)_{5}\right)_{2}\right]^{+}\left[\mathrm{TCNE}^{-} \cdot\right.$.

\section{$57 \mathrm{Ee}$ Mossbaver Spectra}

The room temperature ${ }^{57} \mathrm{Fe}$ Mössbauer spectra of 1-D $\left[\mathrm{Fe}\left(\mathrm{C}_{5} \mathrm{Me}_{5}\right)_{2}\right]^{+} \cdot[\mathrm{TCNE}]^{-} \cdot$ consist of a narrow $(\Gamma=0.323 \mathrm{~mm} / \mathrm{s})$ single transition with an isomer shift $(\delta=0.427 \mathrm{~mm} / \mathrm{s})$ characteristic of low spin Fe(III). Below $12 \mathrm{~K}$ the complex exhibits the onset of a Zeeman split spectra in zero applied field which is fully resolved at $10 \mathrm{~K}$. At $4.23 \mathrm{~K}$ the internal field is $425.6 \mathrm{kOe}$ which is substantially greater than the expected $110 \mathrm{kOe} / \mathrm{spin}$ on the iron atom. In constrast the ${ }^{57} \mathrm{Fe}$ Mössbauer spectra of $\left[\mathrm{Fe}\left(\mathrm{C}_{5} \mathrm{Me}_{5}\right)_{2}\right]^{+} \cdot\left[\mathrm{C}_{3}(\mathrm{CN})_{5}\right]^{-}$does not exhibit any evidence for zero field Zeeman split specta above $1.7 \mathrm{~K}$. The $S=1 / 2$ [TCNE]"radical anion is a dipolar field which induced the Zeeman splitting for the former complex, but not the latter as the anion is $S=0$.

\section{Magnetic Susceptibility}

The magnetic susceptibility of $\left[\mathrm{Fe}\left(\mathrm{C}_{5} \mathrm{Me}_{5}\right)_{2}\right]^{+} \cdot[\mathrm{TCNE}]^{-},\left[\mathrm{Co}\left(\mathrm{C}_{5} \mathrm{Me}_{5}\right)_{2}\right]^{+}[\mathrm{TCNE}]^{-}$, and $\left[\mathrm{Fe}\left(\mathrm{C}_{5} \mathrm{Me}_{5}\right)_{2}\right]^{+} \cdot\left[\mathrm{C}_{3}(\mathrm{CN})_{5}\right]^{-}$above $1.7 \mathrm{~K}$ has been measured by the Faraday technique. The data obeys the Curie-Weiss law, $\chi=C /(T-\theta)$, with $\theta=+30,-1.0$, and $-1.2 \mathrm{~K}$ for $\left[\mathrm{Fe}\left(\mathrm{C}_{5} \mathrm{Me}_{5}\right)_{2}\right]^{+\cdot} \cdot[\mathrm{TCNE}]^{-},\left[\mathrm{Co}\left(\mathrm{C}_{5} \mathrm{Me}_{5}\right)_{2}\right]^{+}[\mathrm{TCNE}]^{-\cdot}$, and $\left[\mathrm{Fe}\left(\mathrm{C}_{5} \mathrm{Me}_{5}\right)_{2}\right]^{+\cdot}\left[\mathrm{C}_{3}(\mathrm{CN})_{5}\right]^{-}$, respectively, Fig. 2. Thus, $\left[\mathrm{Fe}\left(\mathrm{C}_{5} \mathrm{Me}_{5}\right)_{2}\right]^{+} \cdot[\mathrm{TCNE}]^{-}$, has dominant ferromagnetic interactions; whereas the latter pair of complexes comprised of either a $S=1 / 2$ donor or 


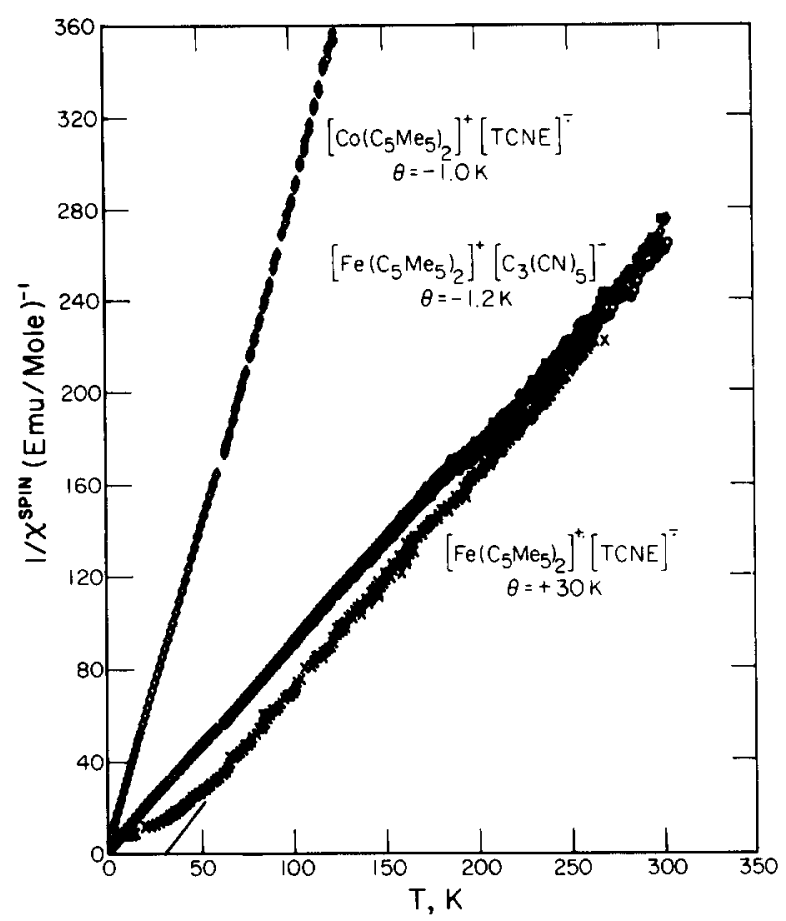

Fig. 2. Fit to the Curie-Weiss expression of $\chi^{-1}$ vs. $T$ for $\left[\mathrm{Fe}\left(\mathrm{C}_{5} \mathrm{Me}_{5}\right)_{2}\right]^{+} \cdot[\mathrm{TCNE}]^{-\cdot} \cdot(75$

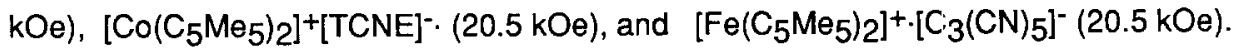

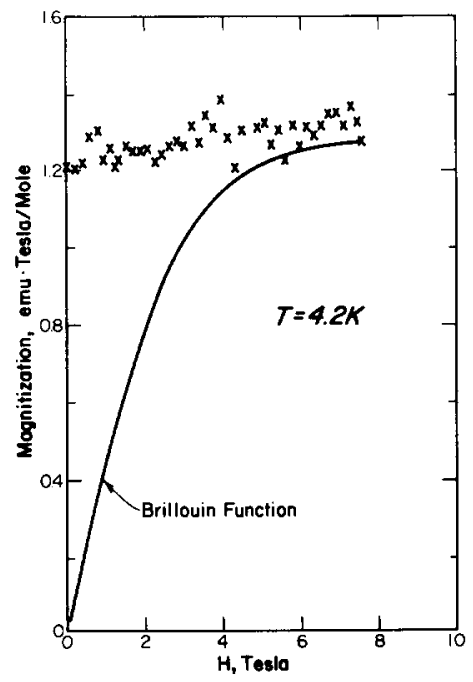

Fig. 3. Saturation magnetization of $\left[\mathrm{Fe}\left(\mathrm{C}_{5} \mathrm{Me}\right)_{2}\right]^{+} \cdot[\mathrm{TCNE}]^{-\cdot}$ as a function of field for 300 $<\mathrm{H}<80,000 \mathrm{Oe}$, at $4.2 \mathrm{~K}$. 
$S=1 / 2$ acceptor, but unlike $\left[\mathrm{Fe}\left(\mathrm{C}_{5} \mathrm{Me}_{5}\right)_{2}\right]^{+} \cdot[\mathrm{TCNE}]^{-} \cdot$ which possesses both a $S=1 / 2$ donor and $S=1 / 2$ acceptor, only weak antiferromagnetic behavior is observed above 1.7 $\mathrm{K}$. For $\mathrm{T}>16 \mathrm{~K}$ preliminary calculations suggest that the data can be fit by a 1-D Heisenberg model with ferromagnetic exchange [2]. For polycrystalline samples the magnetization saturates to a value of $1.1( \pm 0.1) \cdot 10^{4} \mathrm{emu} \cdot \mathrm{Oe} / \mathrm{mol}$ above $300 \mathrm{Oe}$, Fig. 3 . In zero applied field spontaneous magnetization is observed. Using a modified Faraday technique [3] the $\mathrm{M}(\mathrm{H}, \mathrm{T})$ was measured for $\mathrm{H} \geq 0$. Below $4.5 \mathrm{~K}$ the magnetization saturates to $1.1( \pm 0.1) \cdot 10^{4} \mathrm{emu} \cdot \mathrm{Oe} / \mathrm{mol}$ at progessively lower applied fields, Fig. 4 . In zero applied field a spontaneous magnetization of $\sim 2 \cdot 10^{3} \mathrm{emu} \cdot \mathrm{Oe} / \mathrm{mol}$ is observed, Fig. 4. The decrease in magnetization may be due to orientational effects in the polycrystalline sample, domain, formation, or ferrimagnetic behavior. The latter is unlikely as the $\chi^{-1}(T)$ data is atypical for a ferrimagnet [4]. The shapes of the $M(H, T)$ curves are qualitatively as expected for a 3-D bulk ferromagnet.

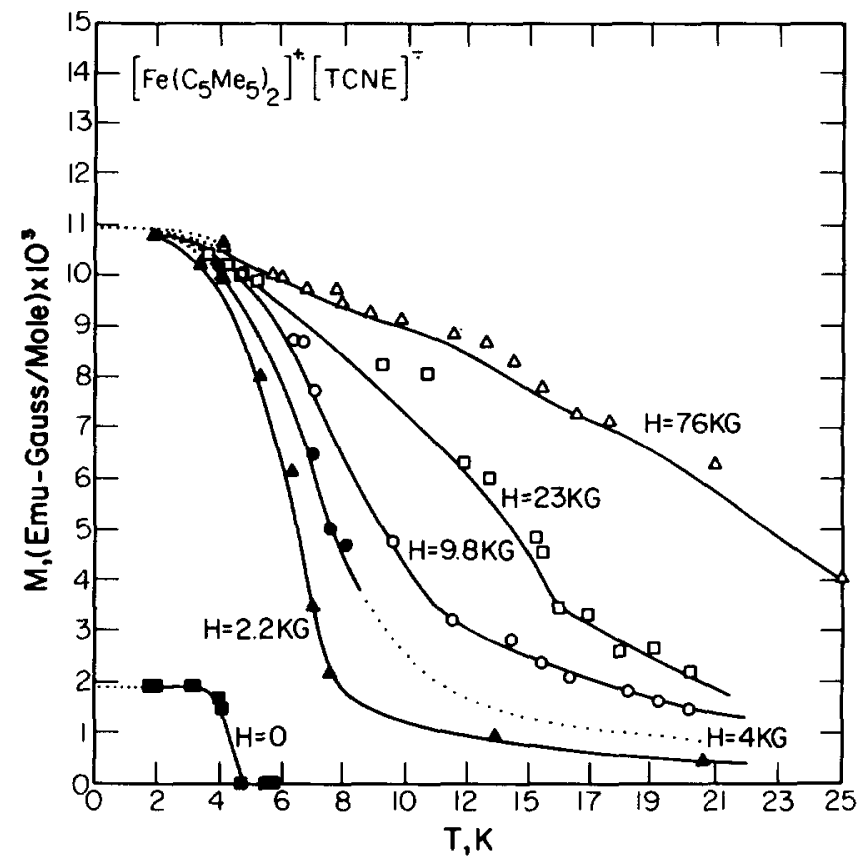

Fig. 4. Temperature dependence of the magnetization as a function of applied field, $M(H, T)$, for polycrystalline samples of $\left[\mathrm{Fe}\left(\mathrm{C}_{5} \mathrm{Me}_{5}\right)_{2}\right]^{+} \cdot[\mathrm{TCNE}]^{-}$.

\section{ACKNOWLEDGEMENTS}

WMR and JHZ gratefully acknowledge the support from NSF DMR Solid State Chemistry Program Grant No. 8313710. IH and DBT thank NSF MR No. 8416511 for partial support. Gratitude is also extended to $S$. McLean (Du Pont CR\&DD) for magnetic susceptibility data. 


\section{REFERENCES}

1 G. A. Candela, L. J. Swartzendruber, J. S. Miller and M. J. Rice, J. Am. Chem, Soc., 101 (1979) 2755.

2 J. S. Miller, J. C. Calabrese, A. J. Epstein, R. W. Bigelow, J. H. Zhang and W. M. Reiff, J. Chem. Soc., Chem. Commun. (1986) in press; J. S. Miller, J. C. Calabrese, H. Rommelmann, S. R. Chittipeddi, J. H. Zhang, W. M. Reiff and A. J. Epstein, submitted.

3 S. R.Chittipeddi, A. J. Epstein and J. S. Miller, manuscript in preparation.

4 J. H. Helms, W. E. Hatfield, M. J. Kwiecien and W. M. Reiff, J. Chem. Phys., 84 (1986) 3993. 